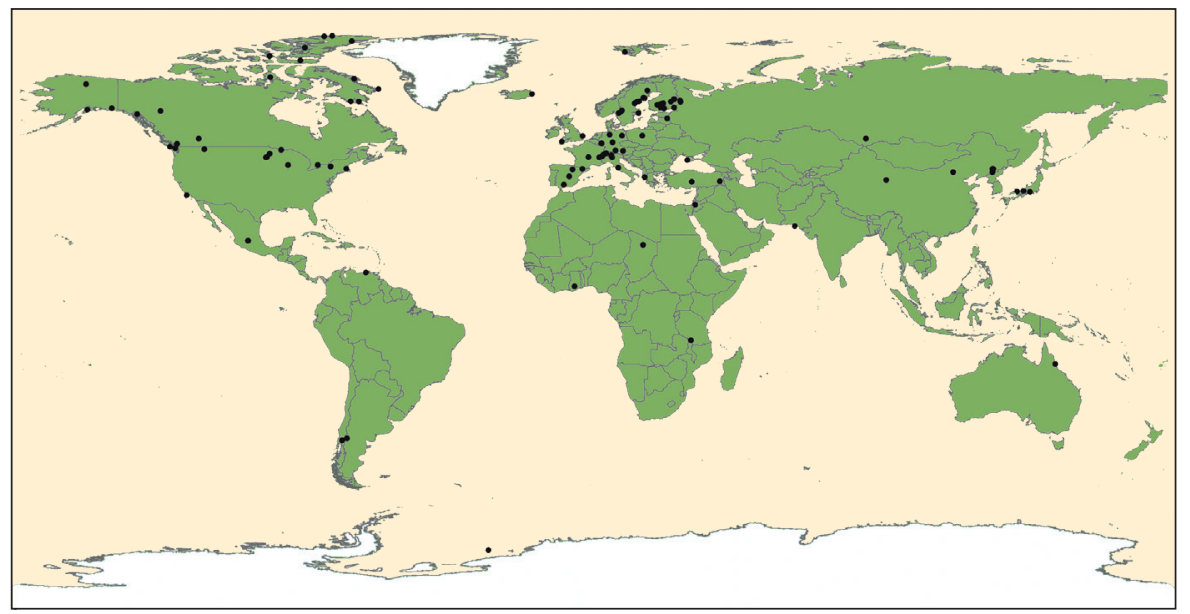

Figure 1: Distribution map of published varved sedimentary records with chronology lengths of at least 100 years. Figure from Ojala et al., in preparation.

the deliverables of the VWG), specifically, an up-to-date metadatabase and inventory of published varved records (Fig. 1). This exercise allowed the group to better identify gaps in reporting methodologies used to establish age-models for varved records, and thus, areas for improvement.

Keynote addresses were delivered by experts from the tree ring, ice core, coral and speleothem communities. By learning from other communities tools and methodologies, the goal was to address perceived or actual weaknesses in varve chronologies and dating (Jansen et al., 2007), that may, in part, be responsible for the sparse usage of varved records in climate known varved records, and to provide recommendations for the publication of varved records including the publication of raw data, a full set of images of the en- tire record, and error estimates. Moreover, it was decided to implement a database of papers dealing with varved sediments, and a metadatabase of varved records on the PAGES website. It was also agreed to produce two group publications, one on protocols and a review about the fidelity of sediment varve chronologies.

A third workshop of the VWG will be held in the Eifel region of Germany, 21-23 March, 2012, focusing mainly on the calibration of varved records for climate reconstructions.

\section{Acknowledgements}

The organizers wish to thank PAGES, INQUA, and the U.S. NSF (EAR-SGP and OCE-MGG Programs) for the generous financial support that made this workshop possible. Support by staff at Texas A\&M University - Corpus Christi was also critical for the success of this workshop, and that support was greatly appreciated.

\section{References}

Francus, P., Ojala, A.E.K., Heinsalu, A., Behl, R., Grosjean, M. and Zolitschka, $B ., 2010$ : Advances in varved sediment studies during the last 10 years, PAGES news, 18(2): 90-91.

Jansen, E., et al., 2007: Palaeoclimate. In: Solomon, S., et al., (Eds.), Climate Change 2007: The Physical Science Basis. Contribution of Working Group I to the Fourth Assessment Report of the Intergovernmental Panel on Climate Change, Cambridge University Press, Cambridge, United Kingdom and New York, NY, USA.

Ojala, A.E.K. and Kosonen, E. (Eds.), 2010: Programme and Abstracts: First workshop of the PAGES Varves Working Group, April 7-9, 2010, Palmse, Estonia, 130 p., online at www.pages-igbp.org/science/ varves/PAGES_VWG_programme_and_abstracts_2010.pdf

\title{
Land-cover reconstructions in the monsoon affected tropical world: Pollen modeling approach and data synthesis
}

\section{IGBP PAGES PHAROS Workshop, Puducherry, India, 27-29 January 2011}

\author{
Anupama Krishnamurthy and Marie-José Gaillard ${ }^{2}$ \\ 'Laboratory of Palynology, French Institute of Pondicherry, Puducherry, India; anupama.k@ifpindia.org \\ ${ }^{2} \mathrm{School}$ of Natural Sciences, Linnaeus University, Kalmar, Sweden
}

This workshop, supported by PAGES and organized under the umbrella of the Golden Jubilee of the Laboratory of Palynology, French Institute of Pondicherry (IFP), was attended by over fifty participants from India and abroad (Sri Lanka, Australia, Sweden, Estonia and France). There was a good mix of participants from different fields (Earth science, ecology, paleoecology, history and archeology) with adequate representation of data producers and modelers. Compiled abstracts of talks, posters and presentations are available at the IFP website (see URL's in supplementary material www.pages-igbp.org/products/newlsetters/ref2011_2.html).

The need for quantifying land cover and land use, and reconstructing climate change in the tropics is well known. Very little has emerged so far in terms of a multidisciplinary synthesis, although much work has been done over the years in South Asia, specifically in the Indian subcontinent. To address this gap and initiate such synthesis, with India and Sri Lanka as a starting point, the workshop aimed to:

i) Bring together paleoecologists, archeologists, historians and ecologists in order to provide a multidisciplinary background

ii) Introduce the novel methodologies applied today to reconstruct past land cover from pollen data in Europe (the NordForsk POLLANDCAL and LANDCLIM networks, e.g., Gaillard et al., 2008, 2010) to the Indian scientific community iii) Achieve a synthesis of relevant historical and archeological data.

After introductory talks on PAGES Focus 4 (Past Human-Climate-Ecosystem Interactions), the LANDCLIM project in Europe and Sugita's Landscape Reconstruction Algorithm (LRA) (Sugita, 2007 a, b), lectures focused on Holocene time chronologies and vegetation history, modern forest ecosystems and the history of human settlements, providing an overview of the Peninsular India background. This was followed by a session on models and methods in pollen-based Holocene vegetation and land-cover reconstruction. Both theoretical and practical aspects were explained, emphasizing the need for pollen productivity estimates. This session concluded 


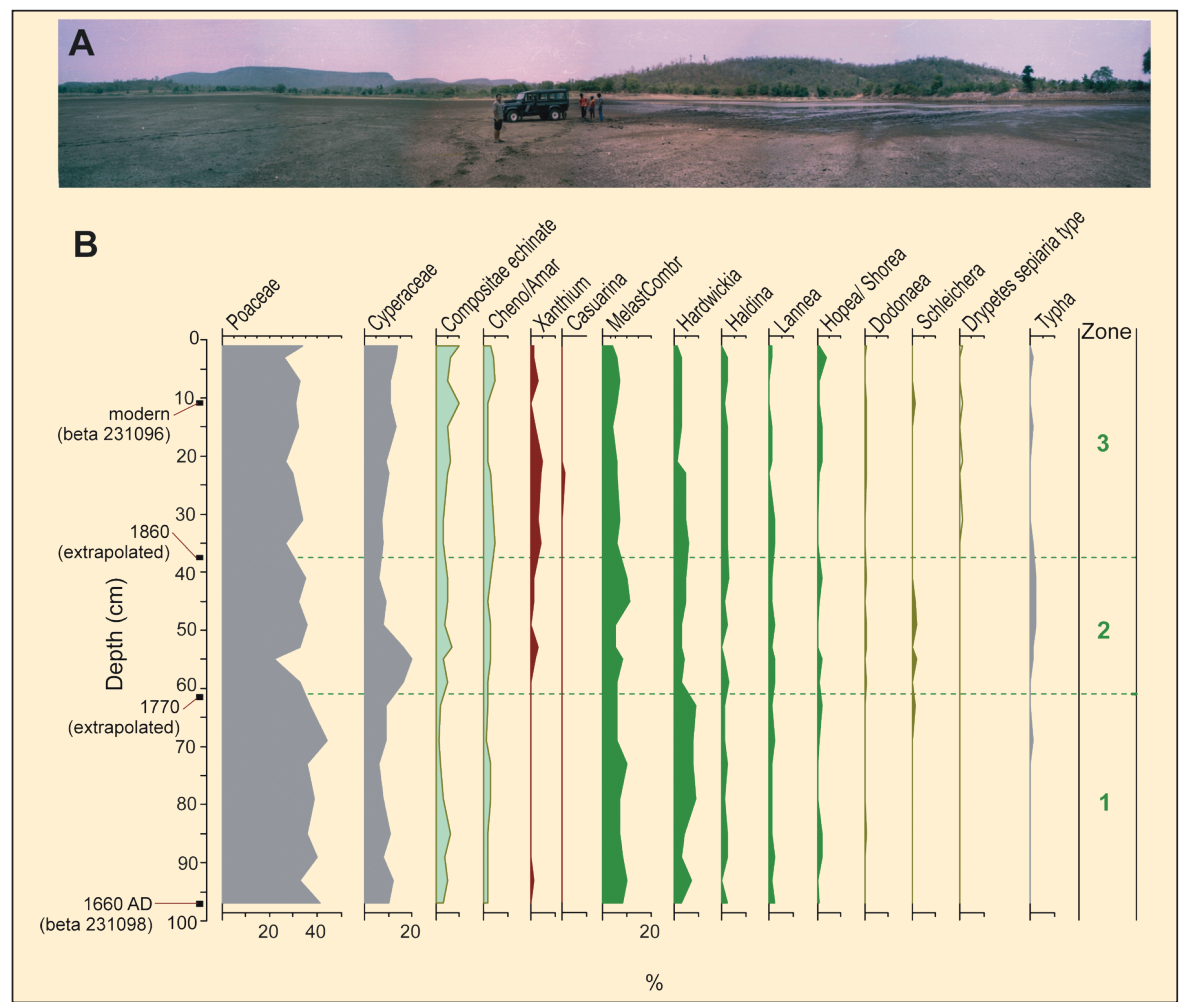

Figure 1: Although there are very few natural lakes in peninsular India, there is an abundance of water reservoirs with artificial levees commonly referred to as "tanks", dotting the landscape of south India (Gunnell and Anupama, 2003). Several thousand tanks cover the south Indian landscape and offer the best potential for pollen-vegetation modeling in this region, of which Potapuram cheruvu $(\boldsymbol{A})$ is an example. A late Holocene pollen diagram from a core in this tank (B; Anupama et al., 2008) illustrates human impact on the landscape (red) as interpreted from markers such as Xanthium (a weed) and Casuarina (common plantation tree) and other plantation trees occurring in tandem but in small proportions (Eucalyptus, Cocos, Tamarindus and Tectona). Significant among the deciduous forest catchment's markers (dark green) are Melastomataceae/Combretaceae, Haldina, Hardwickia, and Lannea.

with a presentation on the first quantitative pollen-inferred Holocene land-cover in northwest Europe achieved within the Swedish LANDCLIM project (Gaillard et al., 2010). Lectures on the second day included an introduction to dynamic vegetation models, tools for spatial analyses, and studies in other regions (tropical Africa and Australasia). The third day comprised of invited talks on the dry evergreen forests of southern India and on the online Historical Atlas of south India (http://www.ifpindia. org/hatlas/). Palynological and multiple proxy studies in southern India, Sri Lanka and Borneo were presented during several lecture and poster sessions (Fig. 1).
As a concrete result of the workshop, three geographical regions of focus on the Indian subcontinent and their respective regional coordinators were identified, (1) Western Himalayas, (2) Eastern Himalayas, and (3) Peninsular India with Sri Lanka. These regions will each move forward in developing the following research themes (with their respective thematic coordinators):

A) Indian pollen database (to be housed at the IFP) and application of the biomization approach.

B) Pollen productivity estimates and landscape reconstruction algorithm application.
C) Archeology and paleoecology (syntheses and databases). Given the diversity of Indian archeology, an investigation into the long-term trends in the environmental context of human adaptation is essential. Starting with collecting all available, environmental proxies from archeological and historical contexts, the plan is to select sites/areas to carry out new case studies with standardized methods to answer specific questions through the establishment of multi-disciplinary research groups.

For the names of regional and thematic coordinators, please see the supplementary material (http://www.pages-igbp.org/ products/newsletters/ref2011_2.pdf) or contact the first author of this report. The research stemming from the above mentioned aims will contribute to the PAGES Focus 4 PHAROS themes of Regional Integration and Land-cover and Use.

A post-workshop excursion to a 30 year afforestation effort of the Sri Aurobindo International Centre of Education, aptly illustrated land-cover changes and positive aspects of human intervention through restoration ecology.

\section{References}

Gaillard, M.-J., et al., 2010: Holocene land-cover reconstructions for studies on land cover climate feedbacks, Climate of the Past, 6 : 483-499.

Sugita, S., 2007a: Theory of quantitative reconstruction of vegetation. I. Pollen from large sites REVEALS regional vegetation, The Holocene, 17: 229-241.

Sugita, S., 2007b: Theory of quantitative reconstruction of vegetation II: all you need is LOVE, The Holocene, 17: 243-257.

Anupama, K., Sudhakar, S., Prasad, S. and Pujar, G.S., 2008: Temporal dynamics using a spatially resolved technology: applying RS to target sites for reconstructing vegetation history in the Eastern Ghats, Proceedings of the National Seminar on Conservation of the Eastern Ghats, December 28-29, 2007, ENVIS Centre, Hyderabad, 474-477.

Gunnell, Y. and Anupama, K., 2003: Past and Present Status of Runoff Harvesting Systems in Dryland Peninsular India: A Critical Review, Ambio, 32(4): 320-324.

For full references please consult:

http://www.pages-igbp.org/products/newsletters/ref2011_2.pdf

\section{0 international workshop on XRF core scanning}

\section{Texel, The Netherlands, 8-10 September 2010}

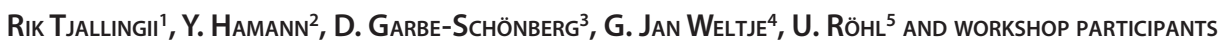

${ }^{1} \mathrm{NIOZ}$-Royal Netherlands Institute for Sea Research, Texel, The Netherlands; Rik.Tjallingii@nioz.nl

${ }^{2}$ Geological Institute, ETH, Zürich, Switzerland; ${ }^{3}$ nnstitute of Geosciences, CAU University of Kiel, Germany; ${ }^{4}$ Department of Geotechnology, Delft University of Technology, The Netherlands; ${ }^{M}$ MARUM-Center for Marine Environmental Sciences, University of Bremen, Germany

Over the last decade, X-ray fluorescence (XRF) core scanning has become an established method for non-destructive and fast acquisition of sediment compositions (i.e., element count rates) directly at the surface of split cores. State-of-the-art core scanners can measure element intensities at sub-millimeter resolution that allow detailed recording of compositional variations in finely laminated and even varved sediments. Core-scanning data are widely applied to paleoceanographic and pa- leoclimate reconstructions on timescales ranging from seasonal to millions of years. New developments in data processing and calibration techniques have increased the need to exchange experiences among users at various laboratories equipped 